Advanced Sampling Theory with Applications 


\section{Advanced Sampling Theory with Applications}

How Michael 'selected' Amy

Volume I

by

Sarjinder Singh

St. Cloud State University,

Department of Statistics,

St. Cloud, MN, U.S.A.

SPRINGER-SCIENCE+BUSINESS MEDIA, B.V. 
A C.I.P. Catalogue record for this book is available from the Library of Congress.

Printed on acid-free paper

All Rights Reserved

(C) 2003 Springer Science+Business Media Dordrecht

Originally published by Kluwer Academic Publishers in 2003

No part of this work may be reproduced, stored in a retrieval system, or transmitted in any form or by any means, electronic, mechanical, photocopying, microfilming, recording or otherwise, without written permission from the Publisher, with the exception of any material supplied specifically for the purpose of being entered and executed on a computer system, for exclusive use by the purchaser of the work. 


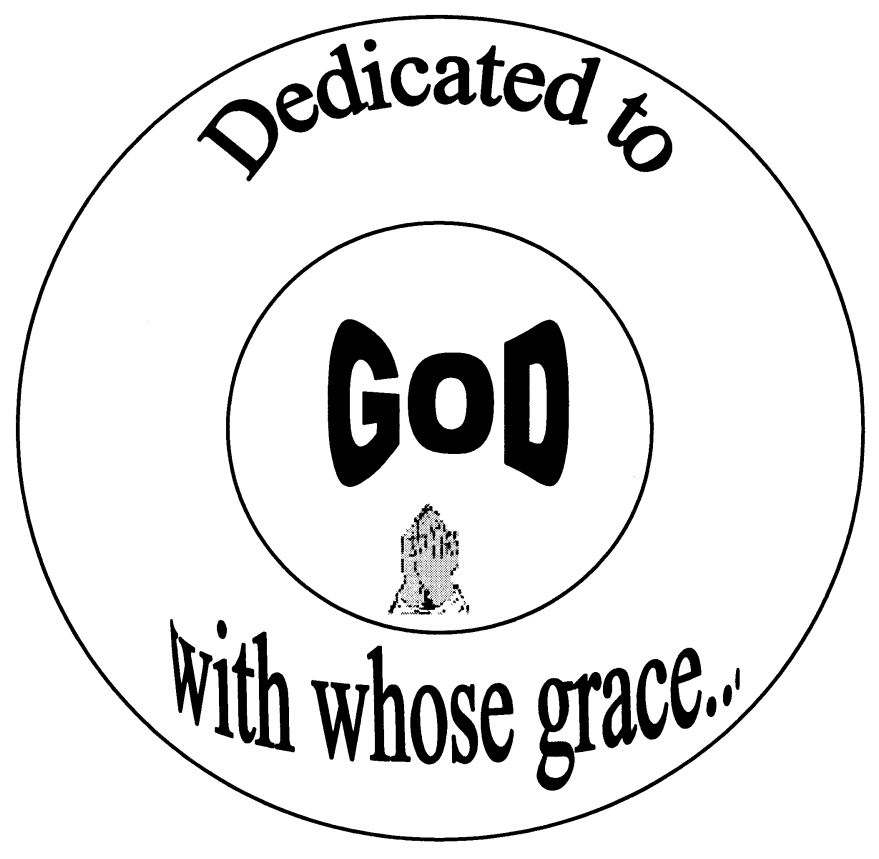




\section{TABLE OF CONTENTS}

\section{Preface}

xxi

\section{BASIC CONCEPTS AND MATHEMATICAL NOTATION}

1.0 Introduction

1.1 Population

1.1.1 Finite population

1.1.2 Infinite population

1.1.3 Target population

1.1.4 Study population

1.2 Sample

1.3 Examples of populations and samples 2

1.4 Census 2

1.5 Relative aspects of sampling versus census 2

1.6 Study variable 2

1.7 Auxiliary variable 3

1.8 Difference between study variable and auxiliary variable 3

1.9 Parameter 3

1.10 Statistic 3

1.11 Statistics 4

1.12 Sample selection 4

1.12.1 Chit method or Lottery method 4

1.12.1.1 With replacement sampling 4

1.12.1.2 Without replacement sampling $\quad 5$

1.12.2 Random number table method $\quad 5$

1.12.2.1 Remainder method 6

$\begin{array}{lll}1.13 & \text { Probability sampling } & 7\end{array}$

$\begin{array}{ll}1.14 & \text { Probability of selecting a sample }\end{array}$

1.15 Population mean/total 8

1.16 Population moments 8

$\begin{array}{lll}1.17 & \text { Population standard deviation } & 8\end{array}$

1.18 Population coefficient of variation $\quad 8$

1.19 Relative mean square error $\quad 9$

1.20 Sample mean 9

1.21 Sample variance 9

$\begin{array}{lr}1.22 \text { Estimator } & 10\end{array}$

$\begin{array}{lll}1.23 & \text { Estimate } & 10\end{array}$

$\begin{array}{lll}1.24 & \text { Sample space } & 10\end{array}$

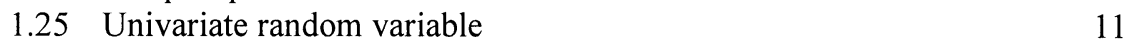

1.25.1 Qualitative random variables 11 
1.25.2 Quantitative random variables

1.25.2.1 Discrete random variable

1.25.2.2 Continuous random variable

1.26 Probability mass function (p.m.f.) of a univariate discrete random variable

1.27 Probability density function (p.d.f.) of a univariate continuous random variable

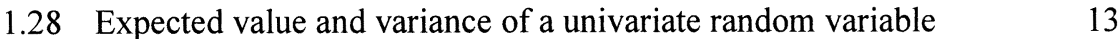

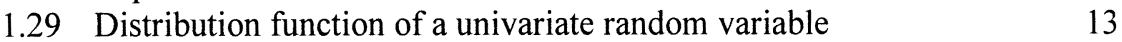

$\begin{array}{ll}\text { 1.29.1 Discrete distribution function } & 14\end{array}$

$\begin{array}{ll}\text { 1.29.2 Continuous distribution function } & 14\end{array}$

$\begin{array}{ll}\text { 1.30 Selection of a sample using known univariate distribution function } & 15\end{array}$

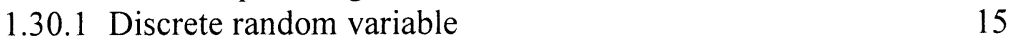

$\begin{array}{ll}\text { 1.30.2 Continuous random variable } & 17\end{array}$

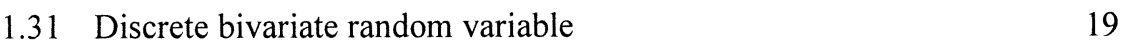

1.32 Joint probability distribution function of bivariate discrete random variables

1.33 Joint cumulative distribution function of bivariate discrete random variables

1.34 Marginal distributions of a bivariate discrete random variable 20

1.35 Selection of a sample using known discrete bivariate distribution function

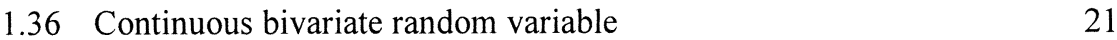

1.37 Joint probability distribution function of bivariate continuous random variable

1.38 Joint cumulative distribution function of a bivariate continuous random variable

1.39 Marginal cumulative distributions of bivariate continuous random variable

1.40 Selection of a sample using known bivariate continuous distribution function

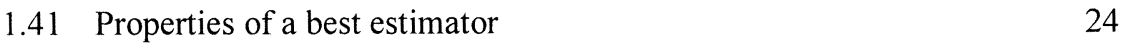

$\begin{array}{ll}1.41 .1 \text { Unbiasedness } & 24\end{array}$

1.41.1.1 Bias 28

$\begin{array}{ll}1.41 .2 \text { Consistency } & 28\end{array}$

$\begin{array}{ll}1.41 .3 \text { Sufficiency } & 28\end{array}$

$\begin{array}{ll}1.41 .4 \text { Efficiency } & 29\end{array}$

1.41.4.1 Variance $\quad 29$

1.41.4.2 Mean square error $\quad 29$

$\begin{array}{ll}1.42 \text { Relative efficiency } & 29\end{array}$

$\begin{array}{ll}1.43 \text { Relative bias } & 29\end{array}$

1.44 Variance estimation through splitting 30

$\begin{array}{ll}1.45 \text { Loss function } & 31\end{array}$

1.46 Admissible estimator 31

$\begin{array}{lll}1.47 & \text { Sample survey } & 31\end{array}$

$\begin{array}{ll}1.48 \text { Sampling distribution } & 32\end{array}$

1.49 Sampling frame 33 
1.50 Sample survey design $\quad 33$

1.51 Errors in the estimators 33

$\begin{array}{ll}1.51 .1 \text { Sampling errors } & 34\end{array}$

$\begin{array}{ll}1.51 .2 \text { Non-sampling errors } & 34\end{array}$

1.51.2.1 Non-response errors $\quad 35$

$\begin{array}{ll}\text { 1.51.2.2 Measurement errors } & 35\end{array}$

$\begin{array}{ll}\text { 1.51.2.3 Tabulation errors } & 35\end{array}$

1.51.2.4 Computational errors $\quad 35$

$\begin{array}{ll}1.52 \text { Point estimator } & 35\end{array}$

$\begin{array}{ll}1.53 \text { Interval estimator } & 35\end{array}$

$\begin{array}{ll}1.54 \text { Confidence interval } & 35\end{array}$

$\begin{array}{ll}1.55 & \text { Population proportion }\end{array}$

$\begin{array}{lll}1.56 & \text { Sample proportion } & 38\end{array}$

$\begin{array}{ll}1.57 & \text { Variance of sample proportion and confidence interval estimates } \quad 39\end{array}$

$\begin{array}{ll}1.58 \text { Relative standard error } & 50\end{array}$

$\begin{array}{ll}1.59 \text { Auxiliary information } & 50\end{array}$

1.60 Some useful mathematical formulae $\quad 56$

$\begin{array}{ll}1.61 \text { Ordered statistics } & 57\end{array}$

$\begin{array}{ll}\text { 1.61.1 Population median } & 57\end{array}$

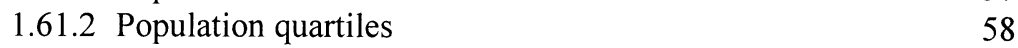

$\begin{array}{ll}1.61 .3 \text { Population percentiles } & 59\end{array}$

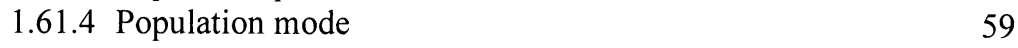

$\begin{array}{ll}1.62 \text { Definition(s) of statistics } & 59\end{array}$

$\begin{array}{ll}1.63 \text { Limitations of statistics } & 60\end{array}$

$\begin{array}{ll}1.64 \text { Lack of confidence in statistics } & 60\end{array}$

$\begin{array}{ll}1.65 & \text { Scope of statistics } \\ & 60\end{array}$

$\begin{array}{ll}\text { Exercises } & 60\end{array}$

$\begin{array}{ll}\text { Practical problems } & 63\end{array}$

\section{SIMPLE RANDOM SAMPLING}

$\begin{array}{lll}2.0 & \text { Introduction } & 71\end{array}$

2.1 Simple random sampling with replacement $\quad 71$

$\begin{array}{ll}2.2 & \text { Simple random sampling without replacement }\end{array}$

$\begin{array}{lll}2.3 & \text { Estimation of population proportion } & 94\end{array}$

$\begin{array}{lll}2.4 & \text { Searls' estimator of population mean } & 103\end{array}$

2.5 Use of distinct units in the WR sample at the estimation stage 106

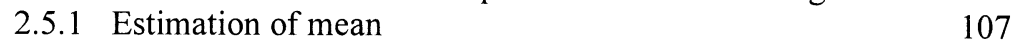

2.5.2 Estimation of finite population variance 113

2.6 Estimation of total or mean of a subgroup (domain) of a population 118

$\begin{array}{lll}2.7 & \text { Dealing with a rare attribute using inverse sampling } & 123\end{array}$

$\begin{array}{ll}2.8 \text { Controlled sampling } & 125\end{array}$

$\begin{array}{lll}2.9 & \text { Determinant sampling } & 127\end{array}$

$\begin{array}{ll}\text { Exercises } & 128\end{array}$

$\begin{array}{ll}\text { Practical problems } & 132\end{array}$ 


\section{USE OF AUXILIARY INFORMATION: SIMPLE RANDOM SAMPLING}

3.0 Introduction 137

3.1 Notation and expected values 137

3.2 Estimation of population mean 138

3.2.1 Ratio estimator 138

3.2.2 Product estimator 145

3.2.3 Regression estimator 149

3.2.4 Power transformation estimator 160

3.2.5 A dual of ratio estimator 161

3.2.6 General class of estimators 164

3.2.7 Wider class of estimators 166

3.2.8 Use of known variance of auxiliary variable at estimation stage of population mean $\quad 167$

$\begin{array}{ll}3.2 .8 .1 \text { A class of estimators } & 167\end{array}$

3.2.8.2 A wider class of estimators $\quad 169$

3.2.9 Methods to remove bias from ratio and product type
estimators

3.2.9.1 Quenouille's method 173

3.2.9.2 Interpenetrating sampling method $\quad 175$

3.2.9.3 Exactly unbiased ratio type estimator $\quad 180$

3.2.9.4 Unbiased product type estimator 183

3.2.9.5 Class of almost unbiased estimators of population ratio and product

3.2.9.6 Filtration of bias 187

3.3 Estimation of finite population variance 191

3.3.1 Ratio type estimator 192

3.3.2 Difference type estimator 197

3.3.3 Power transformation type estimator 198

3.3.4 General class of estimators 199

3.4 Estimation of regression coefficient 203

3.4.1 Usual estimator 203

3.4.2 Unbiased estimator 204

3.4.3 Improved estimators of regression coefficient 207

3.5 Estimation of finite population correlation coefficient 209

3.6 Superpopulation model approach 214

3.6.1 Relationship between linear model and regression 214

3.6.2 Improved estimator of variance of linear regression
estimator

3.6.3 Relationship between linear model and ratio estimator $\quad 221$

3.7 Jackknife variance estimator 223

3.7.1 Ratio estimator 223

3.7.2 Regression estimator 226 
3.8 Estimation of population mean using more than one auxiliary variable

3.8.1 Multivariate ratio estimator 230

3.8.2 Multivariate regression type estimators 231

$\begin{array}{ll}3.8 .3 \text { General class of estimators } & 239\end{array}$

3.9 General class of estimators to estimate any population parameter 245

$\begin{array}{lll}3.10 & \text { Estimation of ratio or product of two population means } & 248\end{array}$

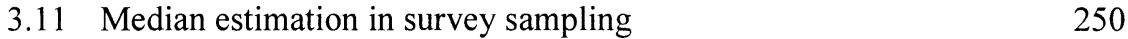

$\begin{array}{ll}\text { Exercises } & 257\end{array}$

$\begin{array}{ll}\text { Practical problems } & 281\end{array}$

\section{USE OF AUXILIARY INFORMATION: PROBABILITY PROPORTIONAL TO SIZE AND WITH REPLACEMENT (PPSWR) SAMPLING}

$\begin{array}{lll}4.0 & \text { Introduction } & 295\end{array}$

4.1 What is PPSWR sampling? 295

4.1.1 Cumulative total method 300

4.1.2 Lahiri's method 303

4.2 Estimation of population total 306

4.3 Relative efficiency of PPSWR sampling with respect to SRSWR sampling

4.3.1 Superpopulation model approach $\quad 312$

$\begin{array}{ll}\text { 4.3.2 Cost aspect } & 315\end{array}$

4.4 PPSWR sampling: More than one auxiliary variable is available $\quad 317$

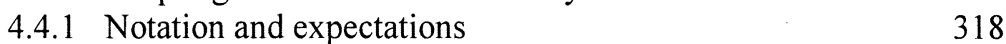

$\begin{array}{ll}4.4 .2 \text { Class of estimators } & 319\end{array}$

$\begin{array}{ll}\text { 4.4.3 Wider class of estimators } & 320\end{array}$

4.4.4 PPSWR sampling with negatively correlated variables $\quad 324$

4.5 Multi-character survey 326

4.5.1 Study variables have poor positive correlation with the selection probabilities. $\quad 326$

4.5.1.1 General class of estimators 335

4.5.2 Study variables have poor positive as well as poor negative correlation with the selection probabilities 336

4.6 Concept of revised selection probabilities 339

4.7 Estimation of correlation coefficient using PPSWR sampling 340

$\begin{array}{ll}\text { Exercises } & 341\end{array}$

Practical problems $\quad 345$ 


\section{USE OF AUXILIARY INFORMATION: PROBABILITY PROPORTIONAL TO SIZE AND WITHOUT REPLACEMENT (PPSWOR) SAMPLING}

5.0 Introduction

5.0.1 Useful symbols $\quad 349$

5.0.2 Some mathematical relations 349

5.1 Horvitz and Thompson estimator and related topics 351

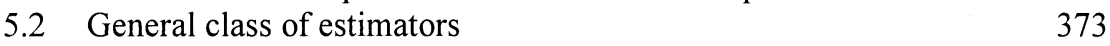

$\begin{array}{ll}5.3 \text { Model based estimation strategies } & 375\end{array}$

5.3.1 A brief history of the superpopulation model 377

5.3.2 Scott, Brewer and Ho's robust estimation strategy 378

5.3.3 Design variance and anticipated variance of linear regression type estimator $\quad 383$

5.4 Construction and optimal choice of inclusion probabilities 385

5.4.1 Pareto $\pi$ ps sampling estimation scheme 386

$\begin{array}{ll}\text { 5.4.2 Hanurav's method } & 387\end{array}$

$\begin{array}{lll}5.4 .3 & \text { Brewer's method } & 388\end{array}$

5.4.4 Sampford's method $\quad 389$

5.4.5 Narain's method $\quad 390$

5.4.6 Midzuno--Sen method 390

5.4.7 Kumar--Gupta--Nigam scheme 391

5.4.8 Dey and Srivastava scheme for even sample size 392

5.4.9 SSS sampling scheme 393

5.4.10 Optimal choice of first order inclusion probabilities 394

$\begin{array}{lll}5.5 & \text { Calibration approach } & 399\end{array}$

5.6 Calibrated estimator of the variance of the estimator of population total

5.7 Estimation of variance of GREG 413

5.8 Improved estimator of variance of the GREG: The higher level calibration approach

5.8.1 Recalibrated estimator of the variance of GREG 424

5.8.2 Recalibration using optimal designs for the GREG 426

5.9 Calibrated estimators of variance of estimator of total and $\begin{array}{ll}\text { distribution function } & 428\end{array}$

5.9.1 Unified setup 430

5.10 Calibration of estimator of variance of regression predictor 431

5.10.1 Chaudhuri and Roy's results 433

5.10.2 Calibrated estimators of variance of regression predictor 436

5.10.2.1 Model assisted calibration $\quad 436$

5.10.2.2 Calibration estimators when variance of auxiliary variable is known 440

5.10.2.2.1 Each component of $V_{x}$ is known 441

5.10.2.2.2 Compromized calibration 442

5.10.2.3 Prediction variance 444 
5.11 Ordered and unordered estimators 444

5.11.1 Ordered estimators $\quad 445$

5.11.2 Unordered estimators $\quad 449$

5.12 Rao--Hartley--Cochran (RHC) sampling strategy 452

5.13 Unbiased strategies using IPPS sampling schemes 462

5.13.1 Estimation of population mean using a ratio estimator 462

5.13.2 Estimation of finite population variance 464

5.14 Godambe's strategy: Estimation of parameters in survey sampling 465

5.14.1 Optimal estimating function $\quad 470$

5.14.2 Regression type estimators $\quad 472$

5.14.3 Singh's strategy in two-dimensional space 473

5.14.4 Godambe's strategy for linear Bayes and optimal
estimation

5.15 Unified theory of survey sampling 479

5.15.1 Class of admissible estimators $\quad 479$

$\begin{array}{ll}5.15 .2 \text { Estimator } & 479\end{array}$

$\begin{array}{ll}\text { 5.15.3 Admissible estimator } & 479\end{array}$

$\begin{array}{ll}\text { 5.15.4 Strictly admissible estimator } & 479\end{array}$

5.15.5 Linear estimators of population total 483

5.15.6 Admissible estimators of variances of estimators of total 485

5.15.6.1 Condition for the unbiased estimator of variance 485

5.15.6.2 Admissible and unbiased estimator of variance $\quad 485$

5.15.6.3 Fixed size sampling design 485

5.15.6.4 Horvitz and Thompson estimator and its variance in two forms

$\begin{array}{ll}\text { 5.15.7 Polynomial type estimators } & 489\end{array}$

5.15.8 Alternative optimality criterion 490

5.15.9 Sufficient statistic in survey sampling 491

5.16 Estimators based on conditional inclusion probabilities 493

5.17 Current topics in survey sampling 494

5.17.1 Survey design 495

5.17.2 Data collection and processing 495

5.17.3 Estimation and analysis of data 496

5.18 Miscellaneous discussions/topics 497

5.18.1 Generalized IPPS designs 497

5.18.2 Tam's optimal strategies 498

5.18.3 Use of ranks in sample selection $\quad 498$

5.18.4 Prediction approach 498

5.18.5 Total of bottom (or top) percentiles of a finite population 499

5.18.6 General form of estimator of variance 499

5.18.7 Poisson sampling 499

5.18.8 Cosmetic calibration $\quad 500$

5.18.9 Mixing of non-parametric models in survey sampling $\quad 501$

5.19 Golden Jubilee Year 2003 of the linear regression estimator 504

Exercises $\quad 507$

$\begin{array}{ll}\text { Practical Problems } & 520\end{array}$ 


\section{USE OF AUXILIARY INFORMATION: MULTI-PHASE SAMPLING}

6.0 Introduction

6.1 SRSWOR scheme at the first as well as at the second phases of the sample selection

6.1.0 Notation and expected values

6.1.1 Ratio estimator

6.1.1.1 Cost function

6.1.2 Difference estimator

6.1.3 Regression estimator

6.1.4 General class of estimators of population mean 541

6.1.5 Estimation of finite population variance 544

6.1.6 Calibration approach in two-phase sampling 545

$\begin{array}{ll}\text { 6.2 Two-phase sampling using two auxiliary variables } & 549\end{array}$

6.3 Chain ratio type estimators $\quad 554$

6.4 Calibration using two auxiliary variables 555

6.5 Estimation of variance of calibrated estimator in two-phase sampling: low and higher level calibration

6.6 Two-phase sampling using multi-auxiliary variables 563

6.7 Unified approach in two-phase sampling 563

6.8 Concept of three-phase sampling $\quad 565$

6.9 Estimation of variance of regression estimator under two-phase sampling

6.10 Two-phase sampling using PPSWR sampling 572

6.11 Concept of dual frame surveys 576

6.11.1 Common variables used for further calibration of weights 576

6.11.2 Estimation of variance using dual frame surveys 577

6.12 Estimation of median using two-phase sampling 578

$\begin{array}{ll}\text { 6.12.1 General class of estimators } & 578\end{array}$

$\begin{array}{ll}6.12 .2 \text { Regression type estimator } & 579\end{array}$

6.12.3 Position estimator $\quad 581$

6.12.4 Stratification estimator $\quad 582$

6.12.5 Optimum first and second phase samples for median estimation

6.12.5.1 Cost is fixed $\quad 584$

6.12.5.2 Variance is fixed $\quad 584$

6.12.6 Kuk and Mak's technique in two-phase sampling 584

6.12.7 Chen and Qin technique in two-phase sampling 586

6.13 Distribution function with two-phase sampling 588

6.14 Improved version of two-phase calibration approach 590

6.14.1 Improved first phase calibration $\quad 590$

6.14.2 Improved second phase calibration $\quad 592$

Exercises $\quad 594$

$\begin{array}{ll}\text { Practical problems } & 612\end{array}$ 


\section{SYSTEMATIC SAMPLING}

$\begin{array}{lll}7.0 & \text { Introduction } & 615\end{array}$

7.1 Systematic sampling $\quad 615$

$\begin{array}{ll}7.2 & \text { Modified systematic sampling }\end{array}$

$\begin{array}{ll}7.3 \text { Circular systematic sampling } & 621\end{array}$

7.4 PPS circular systematic sampling 623

$\begin{array}{ll}7.5 & \text { Estimation of variance under systematic sampling } \\ 724\end{array}$

7.5.1 Sub-sampling or replicated sub-sampling scheme $\quad 625$

7.5.2 Successive differences 626

7.5.3 Variance of circular systematic sampling 627

7.6 Systematic sampling in population with linear trend 627

$\begin{array}{ll}\text { 7.6.1 Estimators with linear trend } & 627\end{array}$

7.6.2 Modification of estimates 629

7.6.3 Estimators based on centrally located samples $\quad 631$

7.6.4 Estimators based on balanced systematic sampling 633

7.7 Singh and Singh's systematic sampling scheme 635

$\begin{array}{lll}7.8 & \text { Zinger strategy in systematic sampling } & 637\end{array}$

7.9 Populations with cyclic or periodic trends 638

$\begin{array}{ll}7.10 & \text { Multi-dimensional systematic sampling }\end{array}$

Exercises $\quad 642$

$\begin{array}{ll}\text { Practical problems } & 646\end{array}$

\section{STRATIFIED AND POST-STRATIFIED SAMPLING}

8.0 Introduction 649

8.1 Stratified sampling $\quad 650$

8.2 Different methods of sample allocation $\quad 659$

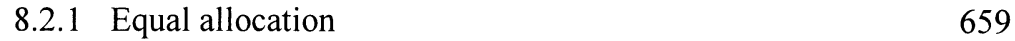

8.2.2 Proportional allocation 659

8.2.3 Optimum allocation method 662

8.3 Use of auxiliary information at estimation stage $\quad 676$

$\begin{array}{ll}\text { 8.3.1 Separate ratio estimator } & 677\end{array}$

8.3.2 Separate regression estimator 681

8.3.3 Combined ratio estimator 684

8.3.4 Combined regression estimator 688

8.3.5 On degree of freedom in stratified random sampling 693

8.4 Calibration approach for stratified sampling design 696

8.4.1 Exact combined linear regression using calibration $\quad 700$

8.5 Construction of strata boundaries 701

8.5.1 Strata boundaries for proportional allocation $\quad 702$

8.5.2 Strata boundaries for Neyman allocation 703

8.5.3 Stratification using auxiliary information 708

$\begin{array}{lll}8.6 & \text { Superpopulation model approach } & 712\end{array}$

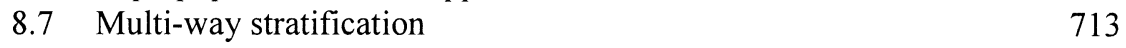


8.8 Stratum boundaries for multi-variate populations 718

8.9 Optimum allocation in multi-variate stratified sampling 723

$\begin{array}{lll}8.10 & \text { Stratification using two-phase sampling } & 726\end{array}$

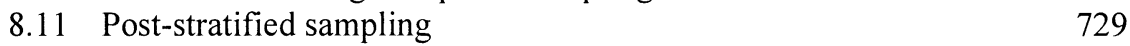

$\begin{array}{ll}\text { 8.11.1 Conditional post-stratification } & 730\end{array}$

8.11.2 Unconditional post-stratification 731

8.12 Estimation of proportion using stratified random sampling 735

Exercises $\quad 738$

$\begin{array}{ll}\text { Practical problems } & 748\end{array}$

\section{NON-OVERLAPPING, OVERLAPPING, POST, AND ADAPTIVE CLUSTER SAMPLING}

9.0 Introduction $\quad 765$

9.1 Non-overlapping clusters of equal size 766

9.2 Optimum value of non-overlapping cluster size $\quad 790$

9.3 Estimation of proportion using non-overlapping cluster sampling 792

9.4 Non-overlapping clusters of different sizes 796

9.5 Selection of non-overlapping clusters with unequal probability 805

9.6 Optimal and robust strategies for non-overlapping cluster sampling 808

$\begin{array}{lll}9.7 & \text { Overlapping cluster sampling } & 812\end{array}$

$\begin{array}{ll}\text { 9.7.1 Population size is known } & 812\end{array}$

$\begin{array}{ll}\text { 9.7.2 Population size is unknown } & 814\end{array}$

$\begin{array}{lll}9.8 & \text { Post-cluster sampling } & 817\end{array}$

$\begin{array}{lr}9.9 \text { Adaptive cluster sampling } & 819\end{array}$

$\begin{array}{ll}\text { Exercises } & 820\end{array}$

Practical problems $\quad 822$

\section{MULTI-STAGE, SUCCESSIVE, AND RE-SAMPLING STRATEGIES}

$\begin{array}{llr}10.0 & \text { Introduction } & 829\end{array}$

$\begin{array}{lll}10.1 & \text { Notation } & 830\end{array}$

10.2 Procedure for construction of estimators of the total 831

10.3 Method of calculating the variance of the estimators 833

10.3.1 Selection of first and second stage units using SRSWOR sampling 834

10.3.2 Optimum allocation in two-stage sampling 836

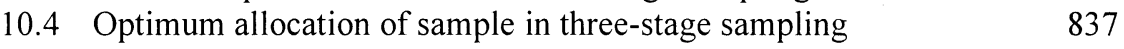

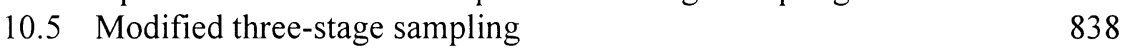

10.6 General class of estimators in two-stage sampling 839

10.7 Prediction estimator under two-stage sampling 842

10.8 Prediction approach to robust variance estimation in two-stage
cluster sampling 
10.8.1 Royall's technique of variance estimation 846

$\begin{array}{lll}10.9 & \text { Two-stage sampling with successive occasions } & 847\end{array}$

10.9.1 Arnab's successive sampling scheme 848

10.10 Estimation strategies in supplemented panels 865

$\begin{array}{lll}10.11 & \text { Re-sampling methods } & 866\end{array}$

10.11.1 Jackknife variance estimator $\quad 867$

10.11.2 Balanced half sample (BHS) method $\quad 871$

10.11.3 Bootstrap variance estimator $\quad 873$

$\begin{array}{ll}\text { Exercises } & 873\end{array}$

$\begin{array}{ll}\text { Practical problems } & 887\end{array}$

\section{RANDOMIZED RESPONSE SAMPLING: TOOLS FOR SOCIAL SURVEYS}

$\begin{array}{llr}11.0 & \text { Introduction } & 889\end{array}$

$\begin{array}{llr}11.1 & \text { Pioneer model } & 889\end{array}$

$\begin{array}{lll}11.2 & \text { Franklin's model } & 892\end{array}$

$\begin{array}{ll}\text { 11.3 Unrelated question model and related issues } & 897\end{array}$

11.3.1 When proportion of unrelated character is known 897

11.3.2 When proportion of unrelated character is unknown $\quad 898$

$\begin{array}{lll}11.4 & \text { Regression analysis } & 903\end{array}$

11.4.1 Ridge regression estimator 905

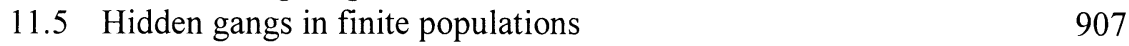

$\begin{array}{ll}\text { 11.5.1 Two sample method } & 907\end{array}$

$\begin{array}{ll}\text { 11.5.2 One sample method } & 911\end{array}$

11.5.3 Estimation of correlation coefficient between two

11.6 Unified approach for hidden gangs 916

11.7 Randomized response technique for a quantitative variable 920

11.8 GREG using scrambled responses 924

11.8.1 Calibration of scrambled responses 925

11.8.2 Higher order calibration of the estimators of variance

$\begin{array}{ll}\text { 11.8.3 General class of estimators } & 930\end{array}$

11.9 On respondent's protection: Qualitative characters 930

11.9.1 Leysieffer and Warner's measure $\quad 930$

11.9.2 Lanke's measure $\quad 932$

11.9.3 Mangat and Singh's two-stage model 933

11.9.4 Mangat and Singh's two-stage and Warner's model at
equal level of protection

11.9.5 Mangat's model $\quad 939$

11.9.6 Mangat's and Warner's model at equal level of protection 940

11.10 On respondent's protection: Quantitative characters 942

11.10.1 Unrelated question model for quantitative data 942

11.10.2 The additive model 943

11.10.3 The multiplicative model 943 
11.10.4 Measure of privacy protection $\quad 944$

11.10.5 Comparison between additive and multiplicative models $\quad 945$

$\begin{array}{ll}11.11 \text { Test for detecting untruthful answering } & 949\end{array}$

$\begin{array}{ll}11.12 \text { Stochastic randomized response technique } & 951\end{array}$

Exercises 954

Practical problems $\quad 972$

\section{NON-RESPONSE AND ITS TREATMENTS}

12.0 Introduction 975

12.1 Hansen and Hurwitz pioneer model 976

$\begin{array}{ll}\text { 12.2 Politz and Simmons model } & 980\end{array}$

12.3 Horvitz and Thompson estimator under non-response 984

12.4 Ratio and regression type estimators 986

12.4.1 Distribution and some expected values 987

12.4.2 Estimation of population mean 987

12.4.3 Estimation of finite population variance 993

12.5 Calibrated estimators of total and variance in the presence of non-response 1000

12.5.1 Estimation of population total and variance 1000

12.5.2 Calibration estimator for the total 1002

12.5.3 Calibration of the estimators of variance 1003

12.5.3.1 PPSWOR Sampling 1005

12.5.3.2 SRSWOR Sampling 1007

12.6 Different treatments of non-response 1009

12.6.1 Ratio method of imputation 1010

12.6.2 Mean method of imputation $\quad 1010$

12.6.3 Hot deck (HD) method of imputation $\quad 1010$

12.6.4 Nearest neighbor (NN) method of imputation 1011

12.7 Superpopulation model approach 1013

12.7.1 Different components of variance 1014

$\begin{array}{lll}12.8 \text { Jackknife technique } & 1016\end{array}$

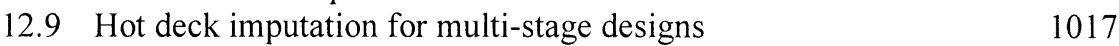

$\begin{array}{ll}12.10 \text { Multiple imputation } & 1021\end{array}$

12.10.1 Degree of freedom with multiple imputation for small samples 1024

$\begin{array}{ll}12.11 \text { Compromised imputation } & 1025\end{array}$

12.11.1 Practicability of compromised imputation $\quad 1027$

12.11.2 Recommendations of compromised imputation $\quad 1027$

$\begin{array}{ll}\text { 12.11.3 Warm deck imputation } & 1028\end{array}$

12.11.4 Mean cum NN imputation $\quad 1028$

$\begin{array}{ll}12.12 \text { Estimation of response probabilities } & 1031\end{array}$

12.13 Estimators based on estimated response probabilities 1033

12.13.1 Estimators based on response probabilities 1035

$\begin{array}{ll}\text { 12.13.2 Calibration of response probabilities } & 1037\end{array}$

12.13.2.1 Calibrated estimator and its variance $\quad 1038$ 
12.13.2.2 Estimation of variance of the calibrated estimator

Exercises

Practical problems

\section{Miscellaneous topics}

13.0 Introduction

1065

13.1 Estimation of measurement errors

13.1.1 Estimation of measurement error using a single measurement per element

13.1.1.1 Model and notation

1066

13.1.1.2 Grubbs' estimators

1066

13.1.2 Bhatia, Mangat, and Morrison's (BMM) repeated measurement estimators

13.1.2.1 Model and notation

13.2 Raking ratio using contingency tables

1073

13.3 Continuous populations

1077

13.4 Small area estimation

13.4.1 Symptomatic accounting techniques

13.4.2 Vital rates method (VRM)

13.4.3 Census component method (CCM)

1082

13.4.4 Housing unit method (HUM)

1083

13.4.5 Synthetic estimator

1083

13.4.6 Composite estimator

1086

13.4.7 Model based techniques

1090

13.4.7.1 Henderson's model

1090

13.4.7.2 Nested error regression model 1093

13.4.7.3 Random regression coefficient model $\quad 1095$

13.4.7.4 Fay and Herriot model 1097

13.4.8 Further generalizations

1097

13.4.9 Estimation of proportion of a characteristic in small areas of a population

1099

Exercises

1101

Practical problems

1101

\section{APPENDIX}

\section{TABLES}

1 Pseudo-Random Numbers (PRN)

2 Critical values based on $t$ distribution

3 Area under the standard normal curve 


\section{Populations}

1 All operating banks: Amount (in \$000) of agricultural loans outstanding in different states in 1997

2 Hypothetical situation of a small village having only 30 older persons (age more than 50 years): Approximate duration of sleep (in minutes) and age (in years) of the persons

3 Apples, commercial crop: Season average price (in $\$$ ) per pound, by States, 1994-1996

4 Fish caught: Estimated number of fish caught by marine recreational fishermen by species group and year, Atlantic and Gulf coasts, 1992-1995

5 Tobacco: Area (hectares), yield and production (metric tons) in specified countries during 1998

6 Age specific death rates from 1990 to 2065 (Number per 100,000 births)

7 State population projections, 1995 and 2000 (Number in thousands) 1124

8 Projected vital statistics by country or area during 2000 1126

9 Number of immigrants admitted to the USA

\section{BIBLIOGRAPHY}

\section{AUTHOR INDEX}

HANDY SUBJECT INDEX 


\section{PREFACE}

Advanced Sampling Theory with Applications: How Michael 'Selected' Amy is a comprehensive exposition of basic and advanced sampling techniques along with their applications in the diverse fields of science and technology.

\section{PURPOSE}

This book is a multi-purpose document. It can be used as a text by teachers, as a reference manual by researchers, and as a practical guide by statisticians. It covers 1179 references from different research journals through almost 2158 citations across 1248 pages, a large number of complete proofs of theorems, important results such as corollaries, and 335 unsolved exercises from several research papers. It includes 162 solved, data based, real life numerical examples in disciplines such as Agriculture, Demography, Social Science, Applied Economics, Engineering, Medicine, and Survey Sampling. These solved examples are very useful for an understanding of the applications of advanced sampling theory in our daily life and in diverse fields of science. An additional 177 unsolved practical problems are given at the ends of the chapters. University and college professors may find these useful when assigning exercises to students. Each exercise gives exposure to several complete research papers for researchers/students. For example, by referring to Exercise 3.1 at the back of Chapter 3, different types of estimators of a population mean studied by Chakrabarty (1968), Vos (1980), Adhvaryu and Gupta (1983), Walsh (1970), Sahai and Sahai (1985) and Sisodia and Dwivedi (1981) are examined. Thus, this single exercise discusses about six research papers. Similarly, Exercise 5.7 explains the other possibilities in the calibration approach considered by Deville and Särndal (1992) and their followers.

The data based problems show statisticians how to select a sample and obtain estimates of parameters from a given population by using different sampling strategies like SRSWR, SRSWOR, PPSWR, PPSWOR, RHC, systematic sampling, stratified sampling, cluster sampling, and multi-stage sampling. Derivations of calibration weights from the design weights under single phase and two-phase sampling have been provided for simple numerical examples. These examples will be useful to understand the meaning of benchmarks to improve the design weights. These examples also explain the background of well known scientific computer packages like CALMAR, GES, SAS, STATA, and SUDAAN, etc., some of which are very expensive, used to generate calibration weights by most organizations in the public and private sectors. The ideas of hot deck, cold deck, mean method of imputation, ratio method of imputation, compromised imputation, and multiple imputation have been explained with very simple numerical examples. Simple examples are also provided to understand Jackknife variance estimation under single phase, two-phase [or random non-response by following Sitter (1997)] and multi-stage stratified designs. 
I have provided a summary of my book from which a statistician can reach a fruitful decision by making a comparison in his/her mind with the existing books in the international market.

\begin{tabular}{|c|c|c|c|c|c|c|}
\hline \multicolumn{7}{|c|}{ Summary Statistic of different components } \\
\hline $\begin{array}{c}\text { General } \\
\text { Information }\end{array}$ & Pages & $\begin{array}{l}\text { Solved } \\
\text { examples }\end{array}$ & $\begin{array}{l}\text { Unsolved } \\
\text { exercises }\end{array}$ & $\begin{array}{l}\text { Practical } \\
\text { problems } \\
\end{array}$ & $\begin{array}{l}\text { No. of } \\
\text { citations }\end{array}$ & $\begin{array}{l}\text { Figures, } \\
\text { tables, maps } \\
\text { and graphs. }\end{array}$ \\
\hline Title (s) & 4 & - & - & - & - & - \\
\hline Dedication & 2 & - & - & - & - & - \\
\hline Table of contents & 14 & - & - & - & - & - \\
\hline Preface & 8 & - & - & - & 9 & 1 \\
\hline 1 & 70 & 13 & 11 & 20 & 2 & 58 \\
\hline 2 & 66 & 20 & 22 & 19 & 58 & 24 \\
\hline 3 & 158 & 36 & 68 & 38 & 307 & 61 \\
\hline 4 & 54 & 9 & 15 & 10 & 84 & 26 \\
\hline 5 & 180 & 13 & 43 & 15 & 651 & 43 \\
\hline 6 & 86 & 10 & 29 & 10 & 170 & 21 \\
\hline 7 & 34 & 8 & 17 & 9 & 72 & 23 \\
\hline 8 & 116 & 21 & 24 & 19 & 112 & 70 \\
\hline 9 & 64 & 12 & 11 & 14 & 61 & 57 \\
\hline 10 & 60 & 3 & 31 & 4 & 162 & 13 \\
\hline 11 & 86 & 3 & 33 & 5 & 216 & 7 \\
\hline 12 & 90 & 8 & 24 & 9 & 154 & 28 \\
\hline 13 & 40 & 6 & 7 & 5 & 100 & 15 \\
\hline Appendix & 26 & - & - & - & - & 12 \\
\hline Bibliography & 62 & - & - & - & - & - \\
\hline Author Index & 22 & - & - & - & - & - \\
\hline Subject Index & 4 & - & - & - & - & - \\
\hline Related Books & 2 & - & - & - & - & - \\
\hline Total & 1248 & 162 & 335 & 177 & 2158 & 459 \\
\hline
\end{tabular}

This book also covers, in a very simple and compact way, many new topics not yet available in any book on the international market. A few of these interesting topics are: median estimation under single phase and two-phase sampling, difference between low level and higher level calibration approach, calibration weights and design weights, estimation of parametric functions, hidden gangs in finite populations, compromised imputation, variance estimation using distinct units, general class of estimators of population mean and variance, wider class of estimators of population mean and variance, power transformation estimators, estimators based on the mean of non-sampled units of the auxiliary character, ratio and regression type estimators for estimating finite population variance similar to proposed by Isaki (1982), unbiased estimators of mean and variance under Midzuno's scheme of sampling, usual and modified jackknife variance estimator, 
estimation of regression coefficient, concept of revised selection probabilities, multi-character surveys sampling, overlapping, adaptive, and post cluster sampling, new techniques in systematic sampling, successive sampling, small area estimation, continuous populations, and estimation of measurement errors.

This book has 459 tables, figures, maps, and graphs to explain the exercises and theory in a simple way. The collection of 1179 references (assembled over more than ten years from journals available in India, Australia, Canada, and the USA) is a vital resource for researcher. The most interesting part is the method of notation along with complete proofs of the basic theorems. From my experience and discussion with several research workers in survey sampling, I found that most people dislike the form or method of notation used by different writers in the past. In the book I have tried to keep these notations simple, neat, and understandable. I used data relating to the United States of America and other countries of the world, so that international students should find it interesting and easy to understand. I am confident that the book will find a good place and reputation in the international market, as there is currently no book which is so thorough and simple in its presentation of the subject of survey sampling.

\section{TIMELINESS AND AUDIENCE}

The objective, style, and pattern of this book are quite different from other books available in the market. This book will be helpful to:

( a ) Graduates and undergraduates majoring in statistics and programs where sampling techniques are frequently used;

( b ) Graduates currently involved in M.Sc. or Ph.D. programs in sampling theory or using sampling techniques in their research;

( c ) Government organizations such as the US Bureau of Statistics, the Statistics Canada, the Australian Bureau of Statistics, the New Zealand Bureau of Statistics, and the Indian Statistical Institute, in addition to private organizations such as RAND and WESTSTAT, etc.

\section{APPROACH}

In this book I have begun each chapter with basic concepts and complete derivations of the theorems or results. I ended each chapter by filling the gap between the origin of each topic and the recent references. In each chapter I provided exercises which summarize the research papers. Thus this book not only gives the basic techniques of sampling theory but also reviews most of the research papers available in the literature related to sampling theory. It will also serve as an umbrella of references under different topics in sampling theory, in addition to clarifying the basic mathematical derivations. In short, it is an advanced book, but provides an exposure to elementary ideas too. It is a much better restatement of the existing knowledge available in journals and books. I have used data, graphs, tables, and pictures to make sampling techniques clear to the learners. 


\section{EXERCISES}

At the end of each chapter I have provided exercises and their solutions are given through references to the related research papers. Exercises can be used to clarify or relate the classroom work to the other possibilities in the literature.

\section{PRACTICAL PROBLEMS}

At the end of each chapter I have provided practical problems which enable students and teachers to do additional exercises with real data.

\section{DATA}

I have taken real data related to the United States of America and many other countries around the world. This data is freely available in libraries for public use and it has been provided in the Appendix of this book for the convenience of the readers. This will be interesting to the international students.

\section{NEW TECHNOLOGIES}

This provides to students or researchers new formulae available in the literature, which can be used to develop new computer programs for estimating parameters in survey sampling and to learn basic statistical techniques.

\section{SOLUTION MANUAL}

I am working on a complete solution manual to the practical problems and selected theoretical exercises given at the end the chapters.

\section{SOME MEMORIES}

I was born in the village of Ajnoud, in the district of Ludhiana, in the state of Punjab, India in 1963. My primary education is from the Govt. Primary School, Ajnoud; the Govt. Middle School, Bilga; and Govt. High School, Sahnewal, which are near my birthplace. I did my undergraduate work at Govt. College Karamsar, Rarra Sahib. Still I remember that I used to bicycle my way to college, about $15 \mathrm{~km}$, daily on the bank of canals. It was fun and that life has never come back. M.Sc. and Ph.D. degrees in statistics were completed at the Punjab Agricultural University (PAU), Ludhiana, and most of the time spent in room no. 46 of hostel no. 5.

I attended conferences of the Indian Society of Agricultural Statistics held at Gujarat, Haryana, Orissa, and Kerala, and was a winner of the Gold Medal in 1994 for the Young Scientist Award. I attended conferences of the Australian Statistical Society in Sydney and the Gold Coast. I attended a conference of the International Indian Statistical Association at Hamilton, and the Statistical Society of Canada conferences at Hamilton, Regina, and Halifax in addition to the Concordia University conference. I also attended the Joint Statistical Meetings (JSM-2001, 2002) at Atlanta and New York. 
At present I am an Assistant Professor at St. Cloud State University, St. Cloud, MN, USA, and recently introduced the idea of obtaining exact traditional linear regression estimator using calibration approach. From 2001 to 2002 I did post doctoral work at Carleton University, Canada. From 2000 to 2001 I was a Visiting Instructor at the University of Saskatchewan, Canada. From 1999 to 2000 I was a Visiting Instructor at the University of Southern Maine, USA, where I taught several courses to undergraduate and graduate students, and introduced the idea of compromised imputation in survey sampling. From 1998 to 1999 I was Visiting Scientist at the University of Windsor Canada. From 1996 to 1998 I was Research Officer-II in the Methodology Division of the Australian Bureau of Statistics where I developed higher order calibration approach for estimating the variance of the GREG, and introduced the concept of hidden gangs in finite populations. From 1995 to 1996 I was Research Assistant at Monash University, Australia. From 1991 to 1995 I was Research Fellow, Assistant Statistician and then Assistant Professor at PAU, Ludhiana, India and was also awarded a Ph.D. in statistics in 1991. I have published over 80 research papers in reputed journals of statistics and energy science. I am also co-author of a monograph entitled, Energy in Punjab Agriculture, published by the Indian Council of Agricultural Research, New Delhi.

Advanced Sampling Theory with Applications is my additional achievement. In this book you can enjoy my new ideas such as:

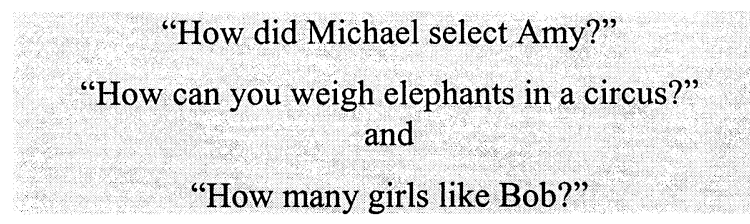

in addition to higher order calibration, bias filtration, hybridising imputation and calibration techniques, hidden gangs, median estimation using two-phase sampling, several new randomised response models, and exact traditional linear regression using calibration technique etc..

\section{ACKNOWLEDGEMENTS}

Indeed the words at my command are not adequate to convey the feelings of gratitude toward the late Prof. Ravindra Singh for his constant, untiring and ever encouraging support since 1996 when I started writing this book. Prof. Ravindra Singh passed away Feb. 4, 2003, which is a great loss to his erstwhile students and colleagues, including me. He was my major advisor in my $\mathrm{Ph} . \mathrm{D}$. and was closely associated in my research work. Since $1996 \mathrm{Mr}$. Stephen Horn, supervisor at the Australian Bureau of Statistics, always encouraged to me to complete this book and I appreciate his sincere co-operation, contribution and kindness in joint research papers as well guidance to complete this book. The help of Prof. M.L. King, Monash University is also appreciated. I started writing this book while staying with Dr. Jaswinder Singh, his wife Dr. Rajvinder Kaur, and their daughter Miss 
Jasraj Kaur in Australia during 1996. Almost seven years I worked day and night on this book, and during May-July, 2003, I rented a room near an Indian restaurant in Malton, Canada to save cooking time and spent most of the time on this book

Thanks are due to Prof. Ragunath Arnab, University of Durban--Westville, for help in completing the work in Chapter 10 related to his contribution in successive sampling, and completing some joint research papers. The help of Prof. H.P. Singh, Vikram University in joint publications is also duly acknowledged.

The contribution of late Prof. D.S. Tracy, University of Windsor, of reading a few chapters of the very early draft of the manuscript has also been duly acknowledged. The contribution of Ms. Margot Siekman, University of Southern Maine in reading a few chapters has also been duly acknowledged. Thanks are also due to a professional editor Kathlean Prenderqast, University of Saskatchewan, for critically checking the grammar and punctuation of a few chapters. Prof. M. Bickis, University of Saskatchewan, really helped me in my career when I was on the road and looking for a job by going from university to university in Canada. Prof. Silvia Valdès and Ms. Laurie McDermott's help, University of Southern Maine, has been much appreciated. Thanks are also due to Professor Patrick Farrell, Carleton University, for giving me a chance to work with him as a post doctoral fellow. Thanks are also due to Prof. David Robinson at SCSU for providing a very peaceful work environment in the department. The aid of one Stat 321 student, Miss Kok Yuin Ong in cross checking all the solved numerical examples, and a professional English editor Mr. Eric Westphal in reading the entire manuscript at SCSU is much appreciated. Thanks are also due to a professional editor Dr. M. Cole from England for editing the complete manuscript, and to bring it in the present form. Mary Shrode and Mitra Sangrovla, Learning Resources and Technology Service, SCSU, for help in drawing a few illustrations using NOVA art explosion 600,000 images collection is duly acknowledged.

I am also thankful to the galaxy of my friends/colleagues, viz., Dr. Inderjit Grewal (PAU), Dr. B.R. Garg (PAU), Dr. Sukhjinder Sidhu (PAU), Prof. L. N. Upadhyaya (Indian School of Mines), Er. Amarjot Singh (Australia), Mr. Qasim Shah (Australia), Mr. Kuldeep Virdi (Canada), Mr. Kulwinder Channa (Canada), Prof. Balbinder Deo (Canada), Er. Mohan Jhajj (Canada), Mr. Gurbakhash Ubhi (Canada), Mr. Gurmeet Ghatore (USA), Dr. Gurjit Sidhu (USA), Prof. Balwant Singh (USA), Prof. Munir Mahmood (USA), and Mr. Suman Kumar (USA). All cannot be listed, but none is forgotten. I met uncle Mr. Trilochan Singh at Ottawa, who changed my style of living a bit and taught me to get involved with other things, not only sampling theory, and I appreciate his advice. I sincerely appreciate Dr. Joginder Singh's advice at Ottawa, who taught me to do meditation imagining the writing of the name of God with eyes closed and I found it helps when under pressure from work. I am most grateful to my teachers and colleagues for their help and co-operation. Special thanks are due to my father Mr. Sardeep Ubhi, my mother Mrs. Ranjit Ubhi for making this book possible, my brothers Jatinder and Kulwinder, and my late sister Sarjinder. 
The permission of Dimitri Chappas, NOAA/ National Climatic Data Center to print a few maps is also duly acknowledged. Free access to data given in the Appendix by Agricultural Statistics and Statistical Abstracts of the United States are also duly acknowledged. I would also like to extend my thanks to the Editor James Finlay, Associate Editor Inge Hardon, and reviewers for bringing the original version of the manuscript into the present form and into the public domain.

Note that I used EXCEL to solve the numerical examples, and while using a hand calculator there may be some discrepancies in the results after one or two decimal places. Further note that the names used in the examples such as Amy, Bob, Mr. Bean, etc., are generic, and are not intended to resemble any real people. I would also like to submit that all opinions and methods of presentation of results in this book are solely the author's and are not necessarily representative of any institute or organization. I tried to collect all recent and old papers, but if you have any published related paper and would like that to be highlighted in the next volume of my book, please feel free to mail a copy to me, and it will be my pleasure to give a suitable place to your paper. To my knowledge this will be the first book, in survey sampling, open to everyone to share contribution irrespective your designation, status, group of scientists, journals names, or any other discriminating character existing in this world, you feel. Your opinions are most welcome and any suggestion for improvement will be much appreciated via e-mail.

Sarjinder Singh (B.Sc., M.Sc., Ph.D., Gold Medalist, and Post Doctorate) Assistant Professor, Department of Statistics, St. Cloud State University, St. Cloud, MN, 56301-4498, USA E-mail: sarjinder@yahoo.com 